\title{
Immunomodulatory effect of Premna odorata volatile oils in Mycobacterium tuberculosis by inhibiting TLR4/NF-кB pathway
}

\author{
Waleed A. Mohammad ${ }^{1 \mathbb{D}}$, Samah S. Abbas $^{2^{+}}{ }^{\mathbb{D}}$, Mona F. Sch
Elham Amin
${ }^{4}$, Mona H. Hetta
${ }^{2}$ 'Department of Biochemistry, Kasr El-Eini Teaching Hospitals, Cairo, Egypt \\ ${ }^{2}$ Department of Pharmacology and Toxicology, Faculty of Pharmacy, Misr International University, Cairo, Egypt \\ ${ }^{3}$ Department of Clinical Pharmacy and Pharmacy Practice, Faculty of Pharmacy, Misr International University, Cairo, Egypt \\ ${ }^{4}$ Department of Pharmacognosy, Faculty of Pharmacy, Beni-Suef University, 62514, Egypt \\ ${ }^{5}$ Department of Pharmacognosy, Faculty of Pharmacy, Fayoum University, 63514, Egypt
}

\section{AR T I C L E IN F O}

Article Type:

Original Article

\section{Article History:}

Received: 18 September 2018

Accepted: 6 December 2018

\section{Keywords:}

Mycobacterium tuberculosis

Premna odorata

TLR-4

NF- $\mathrm{B}$

IL-1 $\beta$

TNF- $\alpha$

\begin{abstract}
A B S T R A C T
Introduction: The development of multi drug resistant (MDR) tuberculosis (TB) and extensively drug resistant (XDR) TB, increased the interest in the usage of medicinal plants that are complementary to antibiotics to improve anti-TB efficacy. The present study aimed to confirm the anti-TB efficacy of volatile oils (VOs) isolated from different parts of Premna odorata in vivo, and moreover, to test the possible involvement of TLR4/NF- $\kappa \mathrm{B}$ signaling pathway in its anti-TB efficacy.

Methods: Thirty mice were divided into six equal groups. Group 1: healthy mice (negative control). Groups 2-6 were injected intravenously with a positive TB solution of purified MeDiPro Mycobacterium tuberculosis (MTB) antigen for 7 days to induce tuberculosis. Group 3-6: TB-injected mice treated respectively with leaves $\mathrm{VO}(300 \mu \mathrm{L} / \mathrm{d})$, young stems $\mathrm{VO}(300$ $\mu \mathrm{L} / \mathrm{d})$, flowers VO and a combination of the three essential VOs (1:1:1). Various immunologic factors and antioxidant activity were evaluated and compared in the groups.

Results: TB-infected mice showed a significant increase in the serum levels of tumor necrosis factor- $\alpha$ (TNF- $\alpha$ ), interferon-gamma (IFN- $\gamma$ ), interleukin (IL) 1- $\beta$ and the mRNA expression levels of toll-like receptor 4 (TLR-4) \& nuclear factor- $\kappa \mathrm{B}$ (NF- $\mathrm{KB}$ ) and a decrease in IL-10 \& total antioxidant capacity (TAC). While pretreatment with VOs extracted from leaves, flowers, young stems and a combination of the three oils reversed these effects.

Conclusion: The immunomodulatory effects of VOs extracted from different parts of $P$. odorata against TB infection involve the TLR-4/NFkB signaling pathway as well as, antioxidant effects, recommending that the use of this plant may help TB infected patients.
\end{abstract}

Implication for health policy/practice/research/medical education:

VOs extracted from Premna odorata have anti-TB activity by acting on TLR-4/NFKB signaling pathway through decreasing the serum levels of TNF- $\alpha$, IFN- $\gamma$, IL1- $\beta$ and the mRNA expression levels of TLR- 4 \& NF- $\kappa B$, and increasing IL-10 \& TAC. Understanding the mechanism and the signaling pathway involving in the anti-tuberculosis activity will help a lot in preparation of new drugs against TB.

Please cite this paper as: Mohammad WA, Abbas SS, Schaalan MF, Elmaidomy AH, Hassan HM, Amin E, et al. Immunomodulatory effect of Premna odorata volatile oils in Mycobacterium tuberculosis by inhibiting TLR4/NF- $\mathrm{B}$ pathway. J Herbmed Pharmacol. 2018;9(1):1-7. doi: 10.15171/jhp.2019.01.

\section{Introduction}

Tuberculosis (TB), which is a long-lasting transmittable disease caused by the bacillus Mycobacterium tuberculosis, has existed for millennia and persists as a major worldwide health threat. The pulmonary as well as extra pulmonary $\mathrm{TB}$, cause ill-health in about 10 million people each year and is one of the highest ten causes of death globally. For the previous 5 years, it has been the foremost cause of death from a single contagious agent, ranking above HIV/ AIDS (1). For that reason, TB stays a significant public health threat internationally, mandating a serious need to develop new anti-TB agents that are helpful in the 
treatment of active and latent TB.

The atypical cell wall of $M$. tuberculosis defends it from the digestion of macrophages and gives it an innate resistance to many antibiotics $(2,3)$. Multiple drug resistance TB (MDR-TB), resistant to the first line combination therapy of antibiotics is becoming fairly obvious with more than 500000 people in the world. Among those patients, about $10 \%$ are predictable to be extensively drug resistant TB (XDR-TB), which is further resistant to a minimum one second-line therapy (4). XDR-TB occasionally needs a 2 -year course of antibiotics with a high cost and can be lethal even with proper treatment $(5,6)$.

Based on the fact of emerging MDR-TB and XDR-TB, there is a developing interest in the usage of medicinal plants that are complementary to antibiotics to improve anti-TB efficacy. Crude extracts of medicinal plants could act as another source of resistance modifying agents as a result of the wide variety of secondary metabolites that could act as potentials for antimicrobials. Plant extracts can bind to proteins causing inhibition of protein-protein interactions; making it effective modulators of host related immune response, mitosis, apoptosis and signal transduction (7).

The genus Premna, family Lamiaceae, contains many species that are spread throughout tropical and subtropical areas. Premna species are used in traditional medicine to treat immune-related diseases, wound healing, inflammation, skin diseases, stomach disorders, as well as their antibacterial and antifungal activities (8).

In the Philippines, the leaves of Premna odorata Blanco are used in a wide variety of cultural applications in headache, fever, cough and cold. Many studies evaluated the activity of the leaves of $P$. odorata and their constituents against $M$. tuberculosis (9). Recently, P. odorata volatile oils (VOa) isolated from different plant organs (leaves, young stems, and flowers) showed significant anti-TB activities (10). Built on the above-mentioned facts; the present study aimed to continue this work and to test the possible involvement of toll-like receptor 4 (TLR-4)/nuclear factor$\kappa \mathrm{B}(\mathrm{NF}-\kappa \mathrm{B})$ signaling pathway in the anti-TB efficacy of the VOs isolated from different parts of $P$. odorata in vivo.

\section{Materials and Methods}

Chemicals and kits

All chemicals were of high analytical grade, obtained from Sigma Chemical Co., Ltd (St. Louis, MO, USA). All kits were the products of Cohesion biosciences limited (London, UK), CUSABIO (Wuhan, China), MyBioSource (San Diego, US). For conventional PCR targeting TRC4, the primer and red dye Master Mix kit were obtained from Bangalore Genei.

\section{Plant materials}

The plant was collected from The Zoo, Giza, Egypt, May; 2017. It was generously identified by Dr. Abd El-Halim A.
Mohammed, Horticultural Research Institute, Flora and Phytotaxonomy Researchers Department, Dokki, Cairo, Egypt. A voucher specimen (2016-BuPD 45) was placed at Department of Pharmacognosy, Faculty of Pharmacy, Beni-Suef University, Egypt.

Preparation of the volatile oils

As described previously (10), the fresh leaves, young stems and flowers (5 kg each) were submitted separately to a hydrodistillation process using Clevenger apparatus for 2 hours at $75^{\circ} \mathrm{C}$. The oils were collected separately, dried over anhydrous sodium sulfate and stored at $4^{\circ} \mathrm{C}$ in air-tight amber glass containers. The yield (V/W \%) was calculated based on the fresh weight of the plant material. The acute toxicity tests and GC/MS spectra of $P$. odorata VOs isolated from leaves, young stems and flowers were shown previously (10).

\section{Animals}

Albino mice with an average body weight of 25-30 g were obtained from the Animal House; NODCAR; Giza; Egypt. The animals were separated into groups of five, fed with normal commercial pellet diet, given water ad libitum and maintained under standard conditions (temperature $24-28^{\circ} \mathrm{C}$, relative humidity $55 \%-10 \%$ and $12 \mathrm{~h}$ light-dark cycle).

In vivo MeDiPro Mycobacterium tuberculosis antigen ELISA technique

The effects of $P$. odorata VOs on the TB infected mice were evaluated. Thirty normal mice (25-30 g) were selected for this study and divided into six groups each contains five mice as follows:

- Group 1: Healthy mice (negative control), given 1 $\mathrm{ml}$ saline. Five groups (Groups 2-6) of tuberculosisinfected mice which were injected intravenously with a positive TB solution of purified MTB antigen ESAT-6 and CFP $(20 \mu \mathrm{g} / \mathrm{mL})$ using a dose of $100 \mu \mathrm{L} / \mathrm{d}$ for seven days. Mice which had sputum specimens positive for acid-fast bacilli (AFB) and/or culture positive for MTB were used in the experiment and classified in groups as follows:

- Group 2: Positive control untreated mice, given $1 \mathrm{~mL}$ saline.

- Group 3: TB-injected mice treated orally through gavages with leaves oil using a dose of $300 \mu \mathrm{L} / \mathrm{d}$.

- Group 4: TB-injected mice treated orally through gavages with young stems oil using a dose of $300 \mu \mathrm{L} / \mathrm{d}$.

- Group 5: TB-injected mice treated orally through gavages with flowers oil using a dose of $300 \mu \mathrm{L} / \mathrm{d}$.

- Group 6: TB-injected mice treated orally through gavages with combination of the three oils (1:1:1) using a dose of $300 \mu \mathrm{L} / \mathrm{d}$.

After 15 days, mice were sacrificed by asphyxiation (CO2 dispensed from a regulated cylinder) followed 
by decapitation. Blood samples were collected from the sublingual vein and were allowed to clot for 10 minutes prior to centrifugation at $3000 \mathrm{rpm}$ for serum separation. Aliquots of serum samples for all groups were stored at $-80^{\circ} \mathrm{C}$ for further determination of biochemical parameters.

Biochemical parameters of TLR4/NF- $\kappa \mathrm{B}$ pathway

Assessment of serum levels of TNF- $\alpha$

Assessment of serum tumor necrosis factor- $\alpha$ (TNF- $\alpha$ ) levels was determined using TNF- $a$ ELISA Kit (MyBioSource, San Diego, USA). Briefly and following the company's instructions, the assay was dependent on the technology of sandwich enzyme-linked immune-sorbent assay. Anti-TNFa polyclonal antibody was pre-covered on top of 96-well plates. The biotin conjugated anti-TNF- $\alpha$ polyclonal antibody was used as recognition antibody. The test samples, standards and biotin conjugated recognition antibody were added to the wells subsequently then washed with a washing buffer. A complex of AvidinBiotin-Peroxidase was added. Then a wash buffer was added to remove the unbound conjugates. Horseradish peroxidase (HRP) enzymatic reaction was visualized using TMB substrates. HRP catalyzed TMB to produce a blue color product which was changed to yellow after the addition of acidic stop solution. The amount of TNFa was proportional to the density of the yellow color captured in plate. In a microplate reader, the O.D. absorbance was read at $450 \mathrm{~nm}$, and the TNFa concentration could be calculated.

\section{Assessment of IL-10 serum levels}

The assay of serum interleukin 10 (IL-10) was done using ELISA kit (CUSABIO, Wuhan, China). Briefly, antibody specific for IL-10 was pre-covered on top of a microplate. Standards and samples were pipetted into the wells and any present IL-10 was bound by the immobilized antibody. A biotin-conjugated antibody specific for IL-10 was then added to the wells after removing any unbound substances. Then, avidin conjugated HRP was added to the wells. After washing to remove any unbound avidinenzyme reagent, a substrate solution was added to the wells. The color produced was proportional to the amount of IL-10 bound in the first step. The color development was stopped and the color intensity was measured.

\section{Assessment of TAC serum levels}

Serum total antioxidant capacity (TAC) was determined by ELISA kit (MyBioSource, San Diego, US). Consistent with the manufacturer, the assay depends on the technique of competitive enzyme immunoassay using a monoclonal anti-TAC antibody and a TAC-HRP conjugate. The buffer and serum sample were incubated together for one hour with TAC-HRP conjugate in pre-coated plate. Afterward, the wells were emptied and washed five times. The wells were then incubated with HRP enzyme substrate to form a blue colored complex. At last, the solution turned yellow after adding a stop solution. In a microplate reader, the color intensity was measured spectrophotometrically at $450 \mathrm{~nm}$. The color intensity was inversely proportional to the concentration of TAC. A standard curve was plotted linking the intensity of the color (O.D.) to the standards' concentration. The TAC concentration in each sample was introduced from the standard curve.

\subsubsection{Assessment of IFN- $\gamma$ serum levels}

The interferon-gamma (IFN- $\gamma$ ) in serum samples was measured quantitatively using ELISA kit (Cohesion biosciences limited, London, UK). This assay employed an antibody specific for IFN- $\gamma$ coated on a 96-well plate. Serum samples and standards were pipetted into the wells and IFN- $\gamma$ presented in the sample was bound to the wells by the immobilized antibody. The wells were washed and biotinylated anti-Rat IFN- $\gamma$ antibody was added. After washing away unbound biotinylated antibody, HRPconjugated streptavidin was added to the wells. The wells were again washed, and a TMB substrate solution was added to the wells. The developed color was comparable to the amount of IFN- $\gamma$ bound. The intensity of the color changed from blue to yellow after the addition of the Stop Solution was measured at $450 \mathrm{~nm}$.

\section{Assessment of $I L-1 \beta$ serum levels}

The serum IL- $1 \beta$ levels were determined by ELISA kit (CUSABIO, Wuhan, China). Briefly, IL-1 $\beta$ specific antibody was pre-coated on a microplate. Standards and serum samples $(100 \mu \mathrm{L})$ were put into the wells and any IL- $1 \beta$ present was bound by the immobilized antibody. A biotin-conjugated IL- $1 \beta$ specific antibody was added to the wells after removing any unbound substances. Avidin conjugated HRP was added to the wells. Washing was done to remove any unbound avidin-enzyme reagent, then a substrate solution was added to the wells. Development of color was proportional to the amount of IL- $1 \beta$ bound in the initial step. The color development was stopped and the color intensity was measured.

\section{Assessment of TLR-4 and NF- $\kappa B$ mRNA expression levels Extraction of RNA}

Total RNA was isolated by Trizol reagent (GIBCO BRL, Life Technologies, Inc., Grand Island, NY, USA).

\section{Quantitative reverse transcriptase-PCR analysis}

The absolute amounts of RNA were too small to be analyzed by Northern analysis. Half a microgram of the total RNA was used in each reverse transcriptase reaction. The quantitative PCR was driven by ABI PRISM 7700 Sequence Detection System (Perkin Elmer, Norwalk, CT, U.S.A.). The primer sequences used for TLR4 were 59-CCTCTGCCTTCACT ACAGAGACTTT-39 and 59TGTGGAAGCCT TCCTGGATG-39, and the TaqMan probe sequence was 59(FAM)-CCTGGTGTAGCCA 
TTGCTGCCAACA-(TAMRA). All results were normalized to $18 \mathrm{~S}$ rRNA. While the primer sequence of NF- $\mathrm{BB}$ mRNA expression was forward primer: 5'-ACAACCCCTTCCAAGTTCCCT-3', and reverse primer (5' TGGTCCCGTGA AATACACCT-3'). The comparative threshold cycle method was used to calculate relative expression of the studied genes. Normalization of all values to the GAPDH gene was done.

\section{Statistical Analysis}

The data were expressed as mean \pm SE (standard error) and statistical analysis was carried out using the one-way ANOVA followed by Tukey test. A level of $P<0.05$ was considered to be significant. The result was interpreted as positive infection for MTB antigen at a concentration $>1.5$ $\mu \mathrm{g} / \mathrm{mL}$.

\section{Results}

Effects of different oil treatments on TNF-a serum levels Mice which were injected intravenously with a dose of $100 \mu \mathrm{L} / \mathrm{d}$ of positive TB solution of purified MTB antigen ESAT- 6 and CFP $(20 \mu \mathrm{g} / \mathrm{mL})$, showed a significant 10 -fold increase in TNF- $\alpha$ serum levels, as compared to the normal healthy mice. Treatment of the infected mice with leaves oil, flowers oil and young stem oil markedly reduced the TNF- $\alpha$ serum levels by $51 \%, 69 \%$ and $62 \%$, respectively, as compared to TB-infected mice. While the combination of the three oils (1:1:1) caused a normalization of TNF- $\alpha$ serum level (92\% decrease, as compared to healthy mice) (Figure 1).

Effects of different oil treatments on IL-10 serum levels TB-infected mice showed a marked decrease $(\sim 78 \%)$ in IL-10 serum levels, when compared to the normal healthy mice (Figure 2). The oral treatment with oils extracted from leaves, flowers, young stem, or the combination of the three oils significantly reversed the IL-10 levels by 2.2 , 3.6, 3 and 5-fold increase, respectively, as compared to TBinfected mice.

Effects of different oil treatments on TAC serum levels The infection with $\mathrm{TB}$ solution obviously reduced the serum TAC in mice by $83 \%$, as compared with healthy mice. VOs extracted from leaves, flowers and young stems caused a significant increase of serum TAC in the infected mice by $3.3,5$ and 4.3 -folds, respectively, the combination of the three oils showed the highest increase in serum TAC (7.5-fold increase), as compared to the TB-infected rats, (Figure 3).

Effects of different oil treatments on IFN- $\gamma$ serum levels TB infection of healthy mice significantly increased the INF- $\gamma$ serum level by 12.7 folds. When these mice were treated with $P$. odorata VOs extracted from leaves, flowers and young stems, INF- $\gamma$ serum levels markedly reduced by 57,79 and $70 \%$, respectively, while the combination of

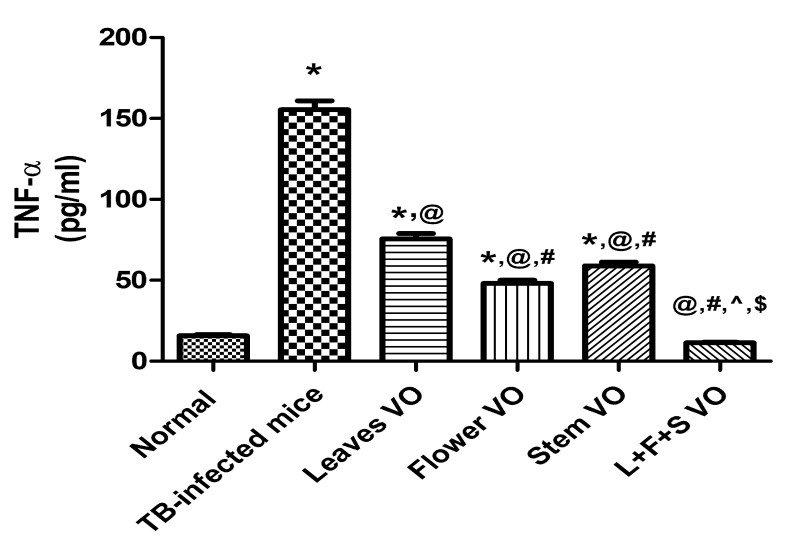

Figure 1. Effect of treatment of TB-infected mice with $P$. odorata volatile oils (300 $\mu \mathrm{L} / \mathrm{d}$; p.o, 15 days) extracted from leaves, flowers, young stem or a combination of the three oils $(1: 1: 1)$ on serum levels of TNF- $\alpha$. Values are means of 5 mice \pm SEM. As compared to normal healthy mice $\left(^{*}\right)$, TB-infected mice (@), TB-infected mice treated with leaves oil (\#), TB-infected mice treated with flowers oil $\left({ }^{\wedge}\right)$, TBinfected mice treated with young stem oil (\$) and TB-infected mice treated with a combination of the three oils (one-way ANOVA followed by Tukey's post-hoc test); $P<0.05$.

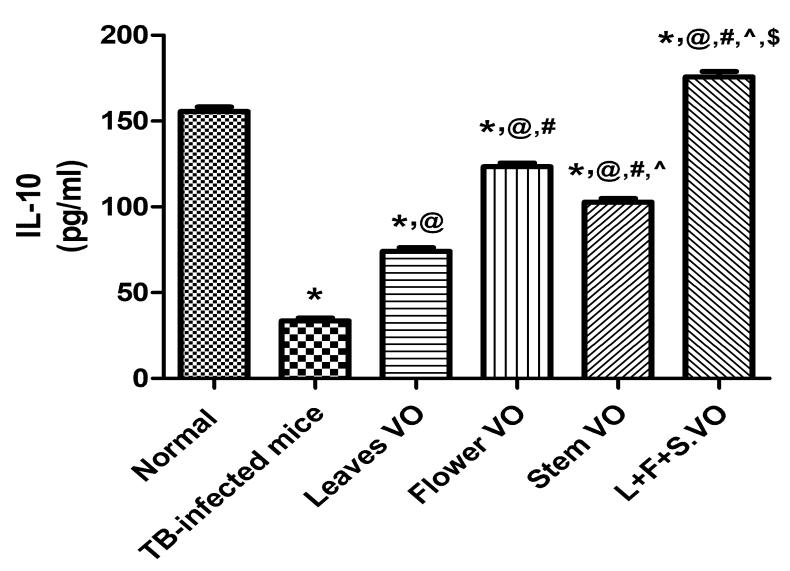

Figure 2. Effect of treatment of TB-infected mice with $P$. odorata volatile oils (300 $\mu \mathrm{L} / \mathrm{d}$; p.o, 15 days) extracted from leaves, flowers, young stem or a combination of the three oils $(1: 1: 1)$ on serum levels of IL-10. Values are means of 5 mice \pm SEM. As compared to normal healthy mice $\left(^{*}\right)$, TB-infected mice (@), TBinfected mice treated with leaves oil (\#), TB-infected mice treated with flowers oil $\left({ }^{\wedge}\right)$, TB-infected mice treated with young stem oil (\$) and TB-infected mice treated with a combination of the three oils (one-way ANOVA followed by Tukey's post-hoc test); $P<0.05$.

the three oils returned the INF- $\gamma$ serum levels of infected mice back to normal (Figure 4).

Effects of different oil treatments on IL- $1 \beta$ serum levels As illustrated in Figure 5, Interleukin-1 $\beta$ serum levels were noticeably increased in TB-infected mice by 7.4 folds, as compared to the serum levels in normal mice. Oral treatment with leaves oil, flowers oil and young stems oil considerably reduced IL- $1 \beta$ serum levels by $70 \%, 74 \%$ 
and $65 \%$, respectively. Similarly, the three oil combination therapy had the highest effect as it was able to return IL-1 $\beta$ to normal mice serum levels.

Effects of different oil treatments on mRNA expression levels of TLR-4

As highlighted in Figure 6, Toll-like receptor-4 (TLR4) relative expression levels were greatly increased ( $\sim 6$ folds) in TB-infected mice, as compared to normal mice. The VO treatment extensively reduced TLR- 4 serum levels by $58 \%$ (leaves oil), 73\% (flowers oil), 67\% (young stems oil) and $80 \%$ (combination of three oils), when compared with infected mice.

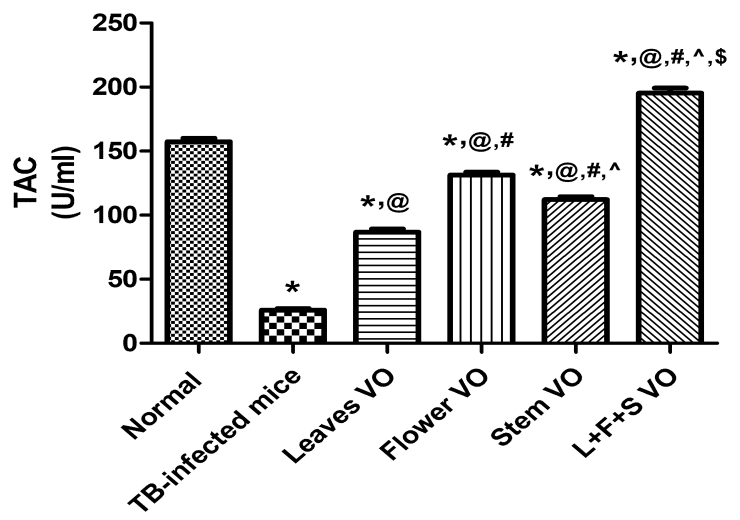

Figure 3 Effect of treatment of TB-infected mice with $P$. odorata volatile oils ( $300 \mu \mathrm{L} / \mathrm{d}$; p.o, 15 days) extracted from leaves, flowers, young stem or a combination of the three oils (1:1:1) on TAC serum levels. Values are means of 5 mice \pm SEM. As compared to normal healthy mice $\left({ }^{*}\right)$, TB-infected mice $\left({ }^{\circledR}\right)$, TB-infected mice treated with leaves oil $(\#)$, TB-infected mice treated with flowers oil $\left({ }^{\wedge}\right)$, TB-infected mice treated with young stem oil $(\$)$ and TB-infected mice treated with a combination of the three oils (one-way ANOVA followed by Tukey's post-hoc test); $P<0.05$

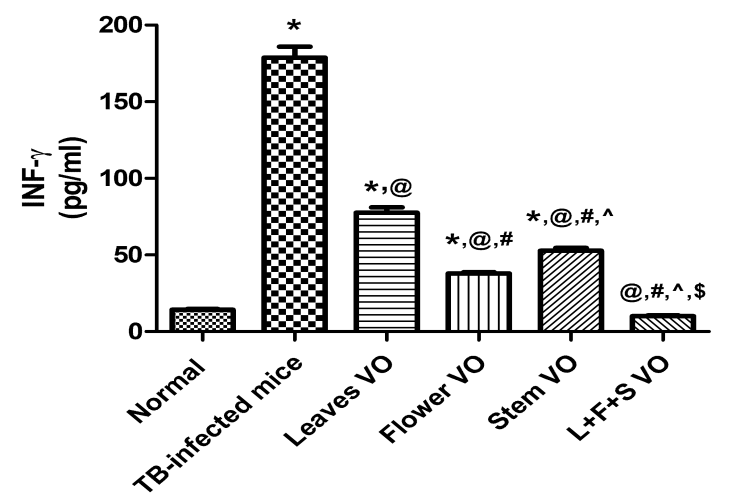

Figure 4. Effect of treatment of TB-infected mice with $P$. odorata volatile oils (300 $\mu \mathrm{L} / \mathrm{d}$; p.o, 15 days) extracted from leaves, flowers, young stem or a combination of the three oils $(1: 1: 1)$ on serum levels of INF- $y$. Values are means of 5 mice \pm SEM. As compared to normal healthy mice $\left({ }^{*}\right)$, TB-infected mice $\left({ }^{\circledR}\right)$, TB-infected mice treated with leaves oil $(\#)$, TB-infected mice treated with flowers oil $\left({ }^{\wedge}\right)$, TB-infected mice treated with young stem oil (\$) and TB-infected mice treated with a combination of the three oils (one-way ANOVA followed by Tukey's post-hoc test); $P<0.05$.
Effects of different oil treatments on mRNA expression levels of NF- $\kappa \mathrm{B}$

In the same way, the TB-infected mice exhibited an increase in mRNA expression levels of NF- $\kappa \mathrm{B}$ by about 19 folds. Oral administration of $P$. odorata VOs extracted from leaves, flowers and young stem oils caused an observable decrease of mRNA expression levels of NF- $\kappa \mathrm{B}$ by 56,78 and $45 \%$, respectively. Again, the combination of the three oils presented a massive decrease in NF- $\kappa \mathrm{B}$ expression levels to the degree that reached to normal levels, as evident in Figure 7.

\section{Discussion}

The results of the present study revealed novel immunomodulatory effects of $P$. odorata VOs in TB

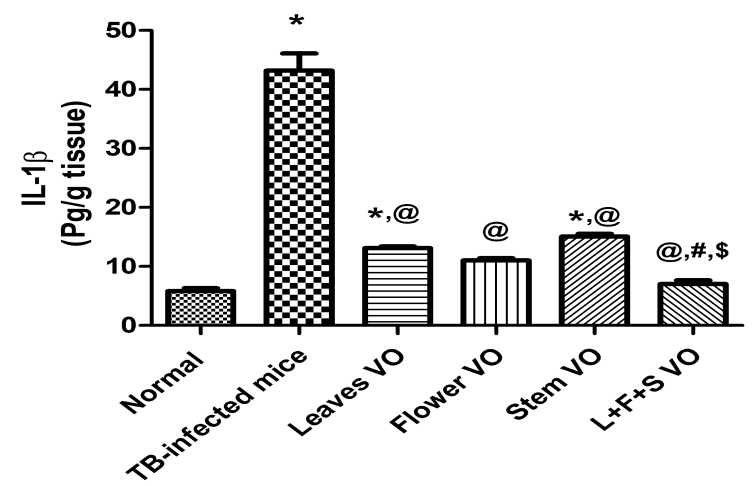

Figure 5. Effect of treatment of TB-infected mice with $P$. odorata volatile oils ( $300 \mu \mathrm{L} / \mathrm{d}$; p.o, 15 days) extracted from leaves, flowers, young stem or a combination of the three oils $(1: 1: 1)$ on serum levels of IL-1 $\beta$. Values are means of 5 mice \pm SEM. As compared to normal healthy mice (*), TB-infected mice (@), TB-infected mice treated with leaves oil $(\#)$, TB-infected mice treated with flowers oil $\left({ }^{\wedge}\right)$, TB-infected mice treated with young stem oil (\$) and TB-infected mice treated with a combination of the three oils (one-way ANOVA followed by Tukey's post-hoc test); $P<0.05$

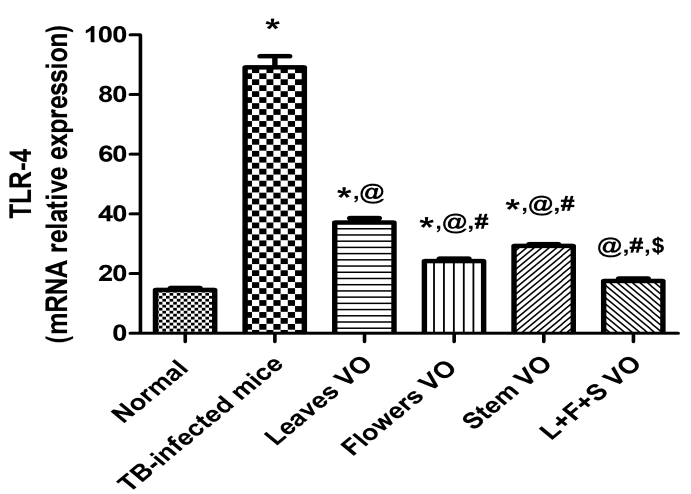

Figure 6. Effect of treatment of TB-infected mice with $P$. odorata volatile oils ( $300 \mu \mathrm{L} / \mathrm{d}$; p.o, 15 days) extracted from leaves, flowers, young stem or a combination of the three oils (1:1:1) on mRNA expression levels of TLR- 4 . Values are means of 5 mice \pm SEM. As compared to normal healthy mice ("), TB-infected mice $\left({ }^{\circledR}\right)$, TBinfected mice treated with leaves oil (\#), TB-infected mice treated with flowers oil $\left({ }^{\wedge}\right)$, TB-infected mice treated with young stem oil $(\$)$ and TB-infected mice treated with a combination of the three oils (one-way ANOVA followed by Tukey's post-hoc test); $P<0.05$. 


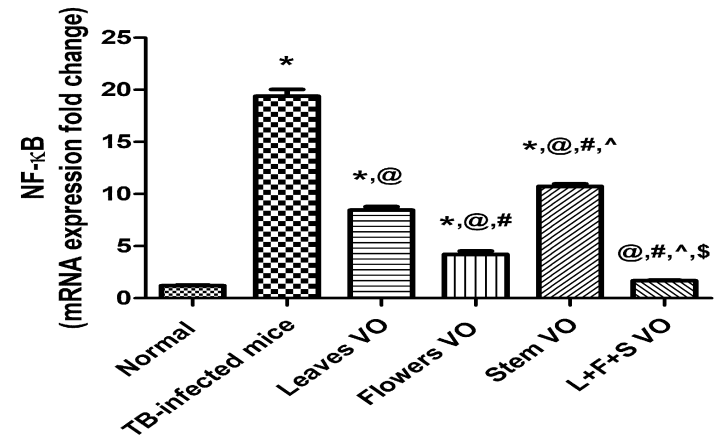

Figure 7. Effect of treatment of TB-infected mice with $P$. odorata volatile oils (300 $\mu \mathrm{L} / \mathrm{d}$; p.o, 15 days) extracted from leaves, flowers, young stem or a combination of the three oils $(1: 1: 1)$ on mRNA expression levels of NF-KB. Values are means of 5 mice \pm SEM. As compared to normal healthy mice $\left({ }^{*}\right)$, TB-infected mice (@), TBinfected mice treated with leaves oil (\#), TB-infected mice treated with flowers oil $\left({ }^{\wedge}\right)$, TB-infected mice treated with young stem oil (\$) and TB-infected mice treated with a combination of the three oils (one-way ANOVA followed by Tukey's post-hoc test); $P<0.05$.

infected mice, evidenced by amelioration of the increased expression levels of TLR- 4 and NF- $\kappa$ B. TLRs have a vital role in the host immune responses against mycobacterial infection and that they are involved in not only immune cells but also other cells. These transmembrane proteins induce a natural immune response to many pathogens. Among them, TLR-2 and TLR-4 that have been identified in association with tuberculosis infection by recognizing various ligands with a lipoprotein structure in the bacilli, then antimicrobial proteins and inflammatory cytokines are synthesized (11).

In a similar pattern, previous studies showed that tuberculosis bacilli stimulate the expression of TLR$4(12,13)$, a finding that proven herein. Stimulation of TLRs by mycobacterial ligands leads to an initiation of intracellular signaling cascades that culminate in the activation of NF-kB, similar to our finding, which then translocate to the nucleus to regulate target gene expression and play important roles in orchestrating proinflammatory responses and innate defense by generation of a variety of antimicrobial effector molecules like TNF- $\alpha$, IL- $1 \beta$ \& IFN- $\gamma$ in addition to the reduction in TAC. Likewise, in the present study, the overexpression of both TLR- 4 as well as NF- $\kappa \beta$ in TB-infected mice was accompanied by a subsequent increase in serum levels of TNF- $\alpha$, IL-1 $\beta$, INF- $\gamma$ and also a decreased TAC level. Decreased TAC levels have been reported in TB patients because of the defect in the host antioxidant defenses and the subsequent oxidative stress, which can be partially restored with antioxidant treatment in addition to malnutrition and poor immunity in these patients $(14,15)$. The treatment of TB-infected mice with the VOs extracted from different plant organs overturned all those previous effects on TNF- $\alpha$, IL- $1 \beta$ and INF- $\gamma$ serum levels, it also increased serum TAC levels suggesting the antioxidant activity of $P$. odorata that also was proved in other studies $(16,17)$. All these effects are suggesting the involvement of TLR-4/ NF- $\kappa \beta$ cascade in the anti-tuberculosis effects of P. odorata VOs.

IL-10 is an inhibitory and anti-inflammatory cytokine that inhibits the ability of myeloid cells such as macrophages and dendritic cells to activate cytokine production from Th1 cells such as TNF- $\alpha$ \& IFN- $\gamma$. Thus IL-10 is an immunosuppressive cytokine that can inhibit macrophage functions, resulting in enhanced intracellular bacterial growth $(18,19)$. Thus, the balance between TNF- $\alpha$ \& IFN- $\gamma$ and IL-10 produced by macrophages against $\mathrm{TB}$ is thought to modulate immune response against TB infection $(20,21)$. This was evident by TB antigen -induced increase in both IFN- $\gamma$ and TNF- $\alpha$ produced by Th1 cells and a decrease in IL-10 produced

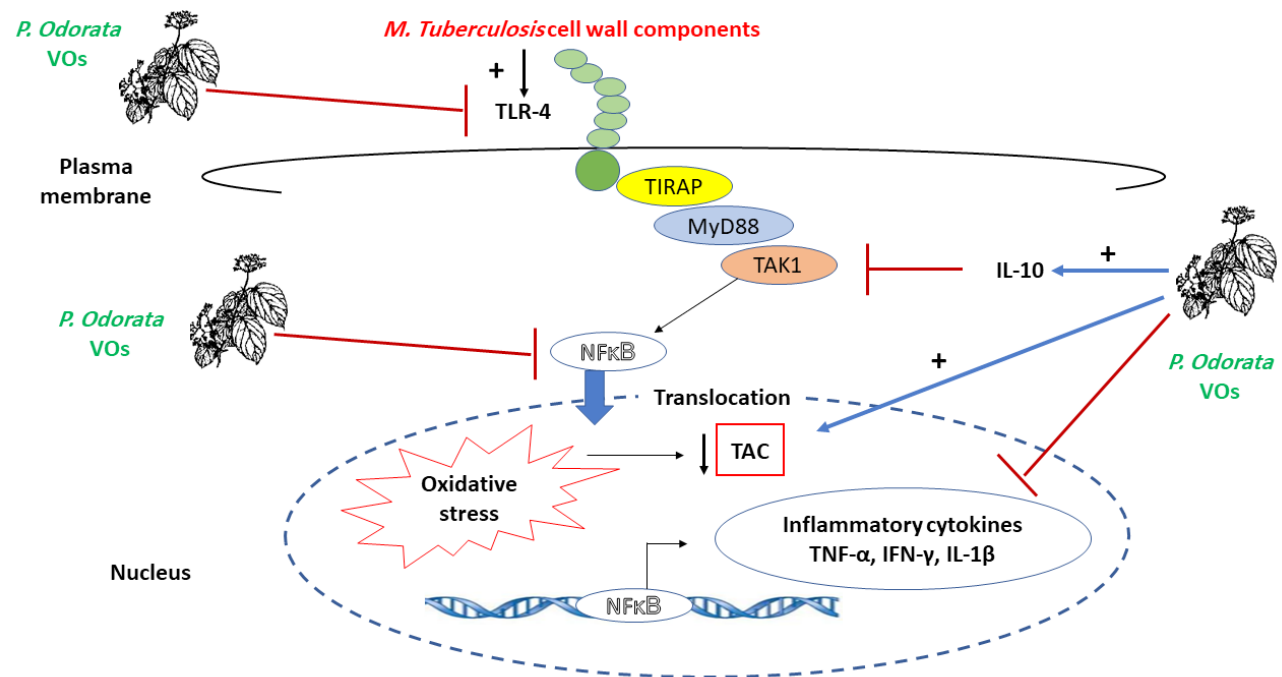

Figure 8. The inhibitory effect of Premna odorata volatile oils on TLR4/NF-KB pathway during Mycobacterium tuberculosis infection. 
by Th2 cells; effects that were reversed by the use of VOs extracted from different plant organs. These targets are illustrated in (Figure 8), highlighting the mechanistic approach, through which the VOs were functioning.

\section{Conclusion}

Accordingly, the results of the present study suggest that the immunomodulatory effects of VOs extracted from the leaves, flowers, stems and combinations of the three extracts $(1: 1: 1)$ of $P$. odorata against TB infection involve the TLR-4/NFkB signaling pathway as well as, antioxidant effects, recommending that the use of this plant may help TB infected patients.

\section{Authors' contributions}

SSA, WAM and MFS contributed to the idea of the study, its design and interpretation. The volatile oil extract was prepared by AHE, HMH, EA and MHH. However, the experimental procedures were done by WAM and SSA under the guidance of MFS. The manuscript was prepared and written by SSA and MFS and approved by all authors.

\section{Competing interests}

None to be declared.

\section{Ethical considerations}

This study was approved by the Ethical Committee of Beni-Suef University (2017-Beni-Suef, Egypt, Approval No. 127). All procedures and techniques used in this study were in accordance with the National Institute of Health Guidelines for the Care and Use of Laboratory Animals (NIH, Department of Health and Human Services publication no. 85-23, revised1985).

\section{Funding/Support}

None.

\section{References}

1. World Health Organization. Report from the first consultation of the Health and Social Protection Action Research \& Knowledge Sharing (SPARKS) Network (WHO/HTM/TB/2017.10). 2017. http://www.who.int/tb/ publications/sparksreport/en/. Accessed 16 August 2017.

2. Flynn JL, Chan J. Immune evasion by Mycobacterium tuberculosis: Living with the enemy. Curr Opin Immunol. 2003;15(4):450-5.

3. Niederweis M, Danilchanka O, Huff J, Hoffmann C, Engelhardt H. Mycobacterial outer membranes: In search of proteins. Trends in Microbiol. 2010;18(3):109-16.

4. Cegielski JP. Extensively drug-resistant tuberculosis: "there must be some kind of way out of here". Clin Infect Dis. 2010;50 Suppl 3:S195-200. doi: 10.1086/651491.

5. Dorman SE, Chaisson RE. From magic bullets back to the magic mountain: the rise of extensively drug-resistant tuberculosis. Nat Med. 2007;13(3):295-8.
6. Kim DH, Hee J, Park SK, et al. Treatment outcomes and long-term survival in patients with extensively drugresistant tuberculosis. Am J Respir Crit Care Med. 2008;178(10):1075-82.

7. Gupta PD, Birdi TJ. Development of botanicals to combat antibiotic resistance. J Ayurveda Integr Med. 2017;8(4):266275.

8. Dianita R, Jantan I. Ethnomedicinal uses, phytochemistry and pharmacological aspects of the genus Premna: a review. Pharm Biol. 2017;55(1):1715-39. doi: $10.1080 / 13880209.2017 .1323225$.

9. Lirio SB, Macabeo AP, Paragas EM, Knorn M, Kohls P, Franzblau SG, et al. Antitubercular constituents from Premna odorata Blanco. J Ethnopharmacol. 2014;154(2):471-4. doi: 10.1016/j.jep.2014.04.015.

10. Elmaidomy AH, Hassan HM, Amin E, Mohamed W, Hetta MH. Premna odorata volatile oil as a new Mycobacterium tuberculosis growth inhibitor for the control of Tuberculosis disease. Eur J Med Plants. 2017;21(4):1-11.

11. Bharti R, Ahuja G, Ganapathy S, Dakappa S. A review on medicinal plants having Antioxidant potential. J Pharmacy Res. 2012;5(8),4278-87.

12. Biyikli OO, Baysak A, Ece G, Oz AT, Ozhan MH, Berdeli A. Role of toll-like receptors in Tuberculosis infection. Jundishapur J Microbial. 2016;9(10):e20224.

13. Basu J, Shin DM, Jo EK. Mycobacterial signaling through toll-like receptors. Front Cell Infect Microbiol. 2012;2:145. doi: 10.3389/fcimb.2012.00145.

14. Selek S, Cosar N, Kocyigit A, et al. PON1 activity and total oxidant status in patients with active pulmonary tuberculosis. Clinic Biochemist. 2008; 41(3):140-4. doi: 10.1016/j.clinbiochem.2007.11.018.

15. Palanisamy GS, Kirk NM, Ackart DF, Shanley CA, Orme IM, Basaraba RJ. Evidence for oxidative stress and defective antioxidant response in guinea pigs with tuberculosis. PloS One. 2011;6(10):e26254. doi: 10.1371/journal. pone.0026254.

16. Komape NP, Aderogba M, Bagla VP, Masoko P, Eloff JN. Anti-bacterial and anti-oxidant activities of leaf extracts of Combretum vendae (Combretecacea) and the isolation of an anti-bacterial compound. Afr J Tradition Compl Alter Med. 2014;11(5):73-7.

17. Arollado EC, Bucog LP, Manalo RA, Sampang IR, Cariscal JJ. Selected Philippine plant extracts as alternative preservatives for a pharmaceutical liquid preparation. Philippine J Sci. 2017;146 (1):7-13.

18. Redford PS, Murray PJ, O'Garra A. The role of IL-10 in immune regulation during $\mathrm{M}$. tuberculosis infection. Mucosal Immunol. 2011;4(3):261-70. doi: 10.1038/ mi.2011.7

19. Shi J, Sun BH, Zhou LR, Wang XS. Role of IL-10 and TNFalpha during Mycobacterium tuberculosis infection in murine alveolar macrophages. Genet Mol Res. 2016;15(3). doi: $10.4238 /$ gmr.15037819.

20. Cooper AM, Mayer-Barber KD, Sher A. Role of innate cytokines in mycobacterial infection. Mucosal Immunol. 2011;4(3):252-60. doi: 10.1038/mi.2011.13.

21. Sakamoto K. The pathology of Mycobacterium tuberculosis infection. Vet Pathol. 2012;49(3):423-39. doi: $10.1177 / 0300985811429313$. 